\title{
HIV Testing Decision and Determining Factors in Ghana
}

\section{Abdul-Karim Iddrisu' ${ }^{1}$, Kwaku Opoku-Ameyaw ${ }^{1}$, Francis Kwame Bukari', Bashiru Mahama², Jerry John Amaasende Akooti ${ }^{2}$}

${ }^{1}$ Department of Mathematics and Statistics, University of Energy and Natural Resources, Sunyani, Ghana

${ }^{2}$ Environmental Health and Sanitation, College of Nursing and Midwifery, Nalerigu, Ghana

Email: karim@aims.ac.za

How to cite this paper: Iddrisu, A.-K., Opoku-Ameyaw, K., Bukari, F.K., Mahama, B. and Amaasende Akooti, J.J. (2019) HIV Testing Decision and Determining Factors in Ghana. World Journal of AIDS, 9, $85-104$.

https://doi.org/10.4236/wja.2019.92007

Received: April 17, 2019

Accepted: June 14, 2019

Published: June 17, 2019

Copyright ( 2019 by author(s) and Scientific Research Publishing Inc. This work is licensed under the Creative Commons Attribution International License (CC BY 4.0).

http://creativecommons.org/licenses/by/4.0/

\section{(c) (i) Open Access}

\begin{abstract}
Knowledge on individual's HIV/AIDS status provides a tool to reduce or avoid HIV transmission, spread and mortalities due to HIV-related illness. However, most people still do not know their HIV status because they are not willing to test for HIV/AIDS due to various reasons. Hence the aim of this paper is to investigate the effects of various risk factors that are likely to influence decision to ever test for HIV/AIDS. The data used in this paper were obtained from the Ghana Demographic and Health Survey ( $\mathrm{n}=1828$ observations and 32 risk factors). We applied the Chi-Square test statistic and the logistic regression model to the data in order to study the effects of these risk factors on one's decision to ever test for HIV. STATA version 14.1 and R version 3.5.2 were used to carry out the statistical analyses. Generally, the results show that education, especially higher education significantly $(\mathrm{OR}=0.53$, $95 \%=0.230,0.837)$ increases the likelihood to ever test for HIV. Also, the younger the age groups the higher the effect and significance in the likelihood to ever test for HIV. We found that HIV-TB co-infection $(\mathrm{OR}=0.53,95 \%=$ $0.165,0.893)$, use of condom anytime one has sex $(\mathrm{OR}=0.31,95 \%=0.054$, $0.573)$, wealth index $(\mathrm{OR}=0.46,95 \%=0.137,0.791)$, awareness of HIV transmission during child-delivery, number of partners significantly affect HIV testing. Those with many partners are less likely $(\mathrm{OR}=-0.26,95 \%=$ $-0.504,-0.007)$ to ever test for HIV and those who know that healthy person may have HIV are more likely ( $\mathrm{OR}=0.41,95 \%=0.137,0.679)$ to ever test for HIV. Age is the common significant risk factor of ever tested for HIV across the 10 regions in Ghana. Resources should be allocated for more education on these significant risk factors in order to help in the fight against HIV-Health related issues.
\end{abstract}

\section{Keywords}

AIDS, Chi-Square Test Statistic, Ghana Demographic and Health Survey, 
HIV, HIV-TB Co-Infection, Logistic Regression Model, Risk Factors

\section{Introduction}

In this paper, we investigate both motivating and discouraging factors that are likely to have a significant impact on one's decision to test for HIV/AIDS in Ghana. A decision to test for HIV/AIDS refers to a situation where an individual decides to voluntarily test for HIV/AIDS with the aim of knowing his/her HIV/AIDS status [1].

The global AIDS response is uncertain as partial success in saving lives and stopping new HIV infections is giving way to complacency [1] [2] [3]. Given the 2020 targets, the pace of progress is not matching the global ambition [1] [2] [3]. The number of AIDS-related deaths is the lowest in this century with fewer than 1 million deaths due to AIDS [1]. Global estimates show that 3 out of 4 people living with HIV now know their status (which is the first step to getting treatment for HIV/AIDS) [1] [3]. At 2018, records of 21.7 million people are on treatment, a net increase of 2.3 million people since the end of 2016 [1] [2] [3]. It is worth noting that the increase in access to treatment should not be taken for granted [3]. This is because from 2019 to 2021, an additional 2.8 million people must be added each year [3]. However, there are no new commitments to increase resources, there is an acute shortage of health-care workers and there is a continuous rise in stigmatization and discrimination [1] [3].

There is HIV prevention crisis and success in saving lives has not been matched with equal success in reducing new HIV infections as new HIV infections are not falling fast enough [1]. Although 1.4 million new HIV infections have been averted since 2010, it is sad to learn that, 180,000 children became infected with HIV in 2017 (which is far from the 2018 target of eliminating new HIV infections among children) [1]. Despite the fact that the overall HIV treatment level is high, children are the most neglected and suffer huge injustice since only half of under-15s living with HIV were being treated in 2017 [1] [3].

Also, stigma and discrimination have terrible consequences. This is because those who are supposed to be protecting, supporting and healing people living with HIV often: 1) discriminate against HIV patients who should be in their care, 2) deny HIV patients access to critical HIV services, resulting in more HIV infections and more deaths [3].

As part of the objectives in the 2030 Agenda for Sustainable Development is the need to end the AIDS epidemic by 2030 [1] [2] [3]. Ending AIDS, as a public health threat, can be interpreted quantitatively as a $90 \%$ reduction in new HIV infections and deaths from AIDS-related illness by 2030 (compared to 2010 baselines). By 2020, the target is to reduce new HIV infections to fewer than 500,000 globally and a reduction in deaths from AIDS-related illness to fewer than 500,000 globally (which approximately a $75 \%$ reduction in both meas- 
ures-death due to HIV and new HIV infections, since 2010) [1] [2] [3].

There is a continuous reduction in deaths due to AIDS-related illness but not quickly enough to reach the General Assembly's 2020 milestone [1] [2] [3]. Globally, annual number of deaths due to AIDS-related illness among people living with HIV (all ages) has declined from 1.9 million (1.4 - 2.7 million) in 2004 to $940,000(670,000-1,300,000)$ in 2017. Since 2010, AIDS-related mortality has declined by $34 \%$. To achieve the 2020 milestone will require further declines of nearly 150,000 deaths per year [3].

The global decline in deaths observed from AIDS-related illness is influenced by progress made in the sub-Saharan Africa, particularly eastern and Southern Africa, which is home to $53 \%$ of the world's people living with HIV [1] [2] [3]. Also, AIDS-related mortality declined by 42\% from 2010 to 2017 in eastern and Southern Africa, influenced by the rapid pace of treatment scale-up in the region. For the western and central Africa, declines were more modest (24\% reduction) [1] [2] [3]. Over the same period, steady declines in deaths also continued in Asia and the Pacific (39\% reduction), western and central Europe and North America (36\% reduction) and the Caribbean (23\% reduction) [1] [2] [3]. In Latin America, where antiretroviral therapy coverage has been relatively high and AIDS-related mortality relatively low for many years, the decline in deaths over the past seven years was $12 \%$. There has been no reduction in AIDS-related mortality in Eastern Europe and central Asia since 2010, and deaths from AIDS-related illness increased by $11 \%$ in the Middle East and North Africa [3].

The reduction in AIDS-related deaths remains higher among women than men [1] [2] [3]. This gender gap is particularly significant in sub-Saharan Africa, where $56 \%$ of people living with HIV are women. Despite the higher disease burden among women, more men living with HIV are dying. In 2017, an estimated 300,000 (220,000 - 410,000) men in sub-Saharan Africa died of AIDS-related illness compared to $270,000(190,000$ - 90,000) women. This reflects higher treatment coverage among women [1] [2] [3]. That is, in 2017, an estimated $75 \%$ of men living with HIV in eastern and southern Africa knew their HIV status, compared to $83 \%$ of women living with HIV of the same age [3].

Globally, new HIV infections continued to decline in 2017 with estimates showing a declined from 3.4 million (2.6 - 4.4 million) in 1996 to 1.8 million (1.4 - 2.4 million) in 2017. However, progress is far slower than what is required to reach the 2020 milestone of less than 500,000 new infections [2] [3] [4].

As observed in the case of AIDS-related mortality, the reduction in new HIV infections between 2010 and 2017 was strongest in sub-Saharan Africa due to sharp reductions in eastern and southern Africa (30\% decline) [1] [2] [3]. Important progress was also made in the Caribbean (18\% decline), in Asia and the Pacific (14\% decline), western and central Africa ( $8 \%$ decline) and western and central Europe and North America (8\% decline). The trend was essentially stable in Latin America (1\% decline). In the Middle East and North Africa and eastern Europe and central Asia, the annual number of new HIV infections has doubled in less than 20 years [3]. 
HIV/AIDS prevalence and related deaths continue to be a concern to Ghanaians. Data obtained from the Ghana Statistical Services showed that prevalence of HIV has declined rapidly from $2.6 \%$ in 2004 to $1.4 \%$ in 2016. These data showed that adults aged 15+ living with HIV are 260,000 with AIDS associated deaths estimated at 15,000. The proportion of female adults aged 15+ living with HIV is $62.27 \%$. The number of children (0 - 14 years) living with $\mathrm{HIV}$ is estimated at 32,000 and HIV prevalence among female aged $15-24$ is $1 \%$. The prevalence of HIV among male aged $15-24$ is lower at $0.4 \%$. Also, the number of AIDS deaths in adults and children is estimated at 18,000. The number of new infections among children aged 0 - 14 is estimated at 3000 and new infections among adults aged $15+$ and children aged $0-14$ is estimated at 20,000. The number of adults aged $15+$ and children aged $0-14$ years living with HIV is $290,000[3]$.

Although many people may have acquired HIV through perinatal or postnatal transmission, most of these infections result from unsafe heterosexual sex [2] [4]. For instance, early initiation of sex, low condom use, and multiple sexual partners contribute to relatively high risk of HIV transmission among adolescents. In addition, poverty, lack of employment, stigmatization, and discrimination may also fuel risky sexual behaviours in young people [4]. Other risk factors include a number of sexual partners, age at first sex, age cohabitation, use condom always. Despite being at high risk, most people have never tested for HIV and therefore do not know their HIV/AIDS status [5]. For instance, in the Sub-Shara African, only $10 \%$ and $15 \%$ of young men and women, respectively, aged 15 - 24 know their HIV status, far below the regional average of $40 \%$ in the general population [4] [5].

Various authors [4] [6] [7] [8] [9] proposed methods to explain why the uptake of HIV testing is still below expected levels among youth. Some of these authors identified a lack of knowledge about where to obtain the test, distance to testing site, or financial problems as some key risk factors that hinder HIV testing. The introduction of the rapid HIV testing procedure, would mean that issues relating to anxiety associated with waiting for test result would no longer significantly hinder HIV testing. However, studies revealed that anxiety related to public reaction in case of a positive result still discourages people from testing [10] [11]. In addition, moral judgments around modes of HIV transmission encourage discrimination and social rejection continues to discourage individuals from testing [12]. Fears around confidentiality of test results undermine the desire to test [13] [14] [15]. Moreover, other studies have pointed to risk perception, spousal and peer pressure, and religious norms as important factors shaping HIV testing decisions [16] [17] [18].

Thus far, it can be observed that to achieve significant success in reducing AIDS-related deaths, there is the need to have knowledge on HIV status of every individual so as to: 1) start HIV treatment early, 2) consider measures to avoid being infected with HIV, or 3) avoid transmission of HIV from infected person to uninfected person, especially during pregnancy and child delivery (transmis- 
sion from mother to child). This paper is devoted to addressing this need by exploring and investigating risk factors (both motivating and discouraging) of HIV testing in Ghana.

\section{Methods}

This section introduces the study setting and the source of data. We also introduce the outcome/dependent variable of interest in this study, as well as risk factors associated with this outcome variable. An outcome variable is a variable whose value/status is being investigated/evaluated. Finally, we discuss some statistical approaches/tools used to analyse these data.

\subsection{Study Setting and Data Source}

This study is conducted in Ghana and the data used for the study are obtained from the Ghana Demographic and Health Survey for 2014. The study used in this study is a cross-sectional, where the outcome variable of interest and its associated risk factors were measured at a single time point.

In this study, we focused on HIV testing data obtained from respondents during the survey. These data consist of 1828 persons, aged 15 - 49, who provided responses on whether they have ever tested for HIV or not. The analyses in this paper then adjusted for risk factors of HIV testing in order to identify significant determinants of one's decision to ever test for HIV. However, the analyses in this paper are based on 1,757 persons since some of the risk factors of HIV testing have missing values [19] [20]. Ethical approval and consent to participate statements can be found on: http://dhsprogram.com/What-We-Do/Protecting-the-Privacy-of-DHS-Survey-R espondents.cfm, approved by the ICF International Institutional Review Board (IRB). We will now introduce the outcome variable and the risk factors of HIV testing.

\subsection{The Outcome Variable of Interest}

In this study, the outcome variable of interest in this study is whether the respondent has "ever tested for HIV" (which takes the value of 0 if you have never tested for HIV or 1 if you have ever tested for HIV).

\subsection{The Risk Factors of HIV-Testing}

The value/status of the outcome variable, introduced in the previous section, depends on certain risk factors/predictors/independent variables. These variables (risk factors/predictors/independent variables) determine/predict the value/status of the outcome variable. In this section, we introduce the risk factors for HIV-testing. These risk factors will be used in the data analyses section to account for their (risk factors) influence on the value/status of the outcome variable (one's decision to ever test for HIV).

Indicators of core knowledge of HIV transmission was recorded by asking 
respondents whether HIV infection could be transmitted through pregnancy and child delivery. The pregnancy risk factor for HIV-testing was recorded 0 if the respondent does not know that HIV can be transmitted during pregnancy (from mother to child) and 1 if the respondent knows. The child delivery risk factor for HIV-testing was recorded 0 if the respondent does not know that HIV can be transmitted during child delivery (from mother, or infected equipment/sources, to child) and 1 if the respondent has knowledge.

The study also investigated the effect of respondent's educational attainment on HIV-testing. This risk factor was recorded as 0 if no education, 1 if primary education, 2 if secondary, and 3 if higher education. We also adjusted for the effect of knowledge on HIV testing site, where respondent is asked if he/she knows where to test for HIV. This risk factor was recorded as 0 if no and 1 if yes.

In order to adjust for the effect of knowledge on HIV prevention approaches, where respondent was asked whether HIV infection could be prevented through being faithful to one sex partner, use of condom any time you have sex, knowing that infected person may look healthy as well. Faithful to one sex partner was coded 0 if respondent answers no and 1 if yes; use of condom any time you have sex was coded 0 if no and 1 if yes; and knowledge that infected person may look healthy was coded 0 if no and 1 if yes. For motivators of HIV testing we controlled for wealth index among the respondents. The wealth index risk factor was coded 0 if respondent was classified as poor and 1 if rich.

This study also adjusts for factors that are likely to influence one's decision to ever test for HIV. These factors are TB awareness, where respondent was asked if he/she is aware that HIV infection could activate latent TB to active TB (takes the value 0 if no and 1 if yes); number sex (continuous variable), where respondent was asked how many time he/she had sex in his/her entire life; heard of sexually transmitted infection (STI), where respondent was asked if he/she has knowledge on STI (takes a value of 0 if no and 1 if yes); residence (takes a value of 0 if urban and 1 if rural); marital status (which takes a value of 0 if single and 1 if married); number of wives (which is continuous variable); continuous age at cohabitation (where respondent was asked for which age he/she started living with the sex partner); and age at first sex (where respondent was asked for the age at which he/she has the first sex); age category (takes value of 0 if age group $15-19,1$ if $20-24,2$ if $24-29,3$ if $30-34,4$ if $35-39,5$ if $40-44$, and 6 if $45-$ 49). We also controlled for religion which takes a value of 0 if respondent is a Christian, 1 if respondent is a Moslem, and 2 if other religion. We account for the effect of the number of wives of the respondent, how many times the respondent has sex in his/her entire life, whether the respondent is willing to care for HIV patient (which take a value of 0 if no and 1 if yes), knowledge of healthy-looking person being an infected person, where respondent was asked whether he/she is aware that a healthy-looking person may have HIV/AIDS (which takes a value of 0 if no and 1 if yes).

The percentage distributions of these variables (outcome variable and the risk factors) are presented in Table 1. It can be observed that high proportion (59\%) 
Table 1. Percentage distribution of the outcome (ever tested for HIV) and the risk factors variables.

\begin{tabular}{|c|c|c|}
\hline Variable & $\mathrm{N}$ & $\%$ or mean \\
\hline \multicolumn{3}{|l|}{ Ever tested for HIV? } \\
\hline No & 751 & 41.08 \\
\hline Yes & 1077 & 58.92 \\
\hline \multicolumn{3}{|l|}{ Aware of TB-HIV co-infection? } \\
\hline No & 186 & 10.18 \\
\hline Yes & 1642 & 89.82 \\
\hline \multicolumn{3}{|l|}{ Use condom any time you have sex? } \\
\hline No & 426 & 24.25 \\
\hline Yes & 1331 & 75.75 \\
\hline \multicolumn{3}{|l|}{ Sex with one partner prevents HIV? } \\
\hline No & 239 & 13.60 \\
\hline Yes & 1518 & 86.40 \\
\hline Mean of the number of sex in life time & 1828 & 2.0043 \\
\hline \multicolumn{3}{|l|}{ Residential status } \\
\hline Urban & 774 & 42.34 \\
\hline Rural & 1054 & 57.66 \\
\hline \multicolumn{3}{|l|}{ Marital status } \\
\hline Married & 1584 & 86.65 \\
\hline Single & 244 & 13.35 \\
\hline Mean of the number of sex partners & 1828 & 1.19 \\
\hline \multicolumn{3}{|l|}{ Wealth index status } \\
\hline Poor & 1584 & 86.65 \\
\hline Rich & 244 & 13.35 \\
\hline \multicolumn{3}{|l|}{ Highest education attained } \\
\hline No education & 678 & 37.09 \\
\hline Primary & 369 & 20.19 \\
\hline Secondary & 707 & 38.68 \\
\hline Higher & 74 & 4.05 \\
\hline \multicolumn{3}{|l|}{ Age group } \\
\hline $15-19$ & 41 & 2.24 \\
\hline $20-24$ & 241 & 13.18 \\
\hline $25-29$ & 384 & 21.01 \\
\hline $30-34$ & 355 & 19.42 \\
\hline $35-39$ & 372 & 20.35 \\
\hline $40-44$ & 265 & 14.50 \\
\hline $45+$ & 170 & 9.30 \\
\hline
\end{tabular}




\section{Continued}

What is your religion?

$\begin{array}{ccc}\text { Christianity } & 1274 & 69.69 \\ \text { Islam } & 419 & 22.92 \\ \text { Others } & 135 & 7.39\end{array}$

Are you willing to take care of HIV person?

No

Yes

Respondent region of residence

Western

$190 \quad 10.39$

Central

Greater Accra

Aware that HIV can be transmitted during child delivery?

$\begin{array}{lcc}\text { No } & 499 & 28.40 \\ \text { Yes } & 1258 & 71.60\end{array}$

Know to test for HIV?

$\begin{array}{lrr}\text { No } & 336 & 19.12 \\ \text { Yes } & 1421 & 80.88\end{array}$

of the respondents ever tested for HIV, many of these respondent (90\%) are aware of TB-HIV co-infection, 75\% of them say they use condom any time they have sex, large proportion (approximately 86\%) of the respondents believe that having sex with one partner can prevent HIV, and mean number of sex among the respondents life time is approximately 2 . The majority (58\%) of the respondents live in rural areas, a large proportion (87\%) of the respondents are married and most of them are poor with approximately $37 \%$ and $38 \%$ of them have no education and secondary education respectively. Most of the respondent aged between 25 - 29 and 30 - 34 and a few fall within the age 15 - 19. Christians are the majority among the respondents (70\%) and many of the respondents say they are willing to take care of HIV person. It can also be observed that majority of the respondents are from the Northern region of Ghana.

\subsection{Statistical Analyses}

In this section, we discuss some selected statistical approaches/tools/indicators 
that will allow us to investigate the presence and degree of association between the outcome variable (ever tested for HIV) and the risk factors of HIV testing, discussed in the previous sections. We also discuss statistical approaches that provide a tool to investigate the magnitude and degree of the relation between the outcome variable of interest and the risk factors of the outcome variable.

In this study, we used two statistical approaches to analyse HIV testing data. Firstly, we used the Chi-Square test statistic [21] to investigate for the presence and degree (significance) of the association between the outcome variable of interest (HIV testing) and the risk factors of HIV testing, introduced in the previous sections. The purpose of this analysis is to search for existence of risk factors that are potential determinants of HIV testing decision. This means that risk factors that are found to have significant/likely to have significant association with the HIV testing will be considered for further analyses. Hence, the explanatory variables discussed in the previous section were considered because they are more likely to have an influence on one's decision to ever test for HIV (HIV testing) in Ghana (see Table 1).

In the further analyses, we used the logistic regression model [22] [23] [24] to establish the relationship and degree (significance) between the outcome variable of interest (HIV testing) and the risk factors/predictors variables. For the logistic regression analysis, we perform comparative analyses by fitting multiple regression models to the HIV testing (ever tested for HIV) by the 10 regions of Ghana adjusting/controlling for the baseline characteristics/risk factors.

The general form of a logistic regression model [22] [23] [24] [25] can be written as

$$
\begin{aligned}
\operatorname{logit}\left[\operatorname{Pr}\left(y_{i}=1 \mid \boldsymbol{X}, \boldsymbol{\beta}\right)\right] & =\operatorname{logit}\left(p_{i}\right)=\log \left(\frac{p_{i}}{1-p_{i}}\right) \\
& =\beta_{0}+\beta_{1} X_{1}+\beta_{2} X_{2}+\cdots+\beta_{p} X_{p},
\end{aligned}
$$

where $x_{1}, \cdots, x_{p}$ are the risk factors/predictors/independent variables; $\beta_{0}, \cdots, \beta_{p}$ are parameter estimates representing the effects of their corresponding risk factors on the binary outcome (HIV testing) variable $y_{i}$, which equals 1 if an individual $i$ has ever tested for HIV and 0 if never tested for HIV; $\boldsymbol{X}$ is a design matrix for the risk factors variables; $\boldsymbol{\beta}$ is a vector of the parameter estimates. Also, $p_{i}$ is probability of ever tested for HIV and $\frac{p_{i}}{1-p_{i}}$ is the odds of the outcome variable among those who exposed to the risk factor relative to those who are not exposed to the same risk factor variable. So in effect, the $\boldsymbol{\beta}$ is the log odds ratio of the outcome variable for those exposed relative to those who are not exposed. These statistical models/analyses were implemented using $\mathrm{R}$ version 3.5.2 [26] [27] [28] and STATA version 14.1 softwares [29] [30].

\section{Results}

In this section, we present and discuss the results obtained using the Chi-Square test statistic, where the focus is to establish the presence and degree (signific- 
ance) of statistical association between the outcome variable ("ever tested for HIV") and the various risk factors in Table 1. Thereafter, we applied the logistic regression model (1) to the binary response/outcome variables of interest ("ever tested for HIV") in order to study the effect and degree (significance) of the risk factors variables on the status of the outcome variable.

\subsection{Results from the Chi-Square Test Statistic}

Table 2 presents the results of the Chi-Square test of association between the outcome variables and the risk factors. The purpose of this exercise is to identify risk factors that more likely to predict the status of the outcome variable ever tested for HIV. The risk factors, based on the results of the Chi-Square test statistic, presented in Table 2 are potential determinants of the status of one's decision to ever test for HIV since these results show a significant association between the outcome variable and the risk factors (presented in Table 1). However, marital status including other risk factors such as knowledge of HIV transmission during pregnancy (Chi-Square $=0.2501, \mathrm{p}$-value $=0.6170$ ) and breast-feeding (Chi-Square $=0.0470$, p-value $=0.828)$, number sex in respondents' entire life time $(\mathrm{t}$-value $=0.022$, $\mathrm{p}$-value $=0.4913)$ variables, were not statistically significant and hence are not considered for the further analyses (using the logistic regression model).

\subsection{Results from the Logistic Regression Model}

In this section, we build a logistic regression model to establish the relationship, and to assess the significance of this relationship, between the outcome and the risk factors variables presented in Table 2. More specifically, we assessed the effects of these risk factors on the outcome variable ("ever tested for HIV") and then assessed the significance of these risk factors effects on this outcome variable. The unadjusted and adjusted odds ratios, from the best fitting logistic regression model, are presented in Table 3.

The results in Table 3 show that those who are aware of HIV-TB co-infection are more likely to ever test for HIV relative to those who are not aware and respondents who say they use condom anytime they have sex are more likely to ever test for HIV compared with those who do not use condom all the time when they have sex. This finding suggests/implies that those who use condom anytime they have sex are also more interested in knowing their HIV status. There is a reduced risk of the respondent to ever test for HIV if the respondent lives in a rural area. However, when we controlled for additional risk factors (under the adjusted odds ratios), we found that this reduction is not statistically significant (OR $=-0.26,95 \%=-0.540,0.568)$. Those who believe in having sex with one partner are more likely to ever test for HIV compared with those who do not agree that having sex with one partner prevents HIV. This seems to suggest that those who believe that HIV spread can be prevented by having one sexual partner also care much to know their HIV status. 
Table 2. A Chi-Square test of association between outcome variable and the risk factors.

\begin{tabular}{|c|c|c|}
\hline \multirow{2}{*}{ Variable } & \multicolumn{2}{|l|}{ Ever tested for HIV } \\
\hline & No & Yes \\
\hline Aware of TB-HIV co-infection? & Chi-Square $=34.93, \mathrm{p}$-vale $<0.001$ & \\
\hline No & 114 & 72 \\
\hline Yes & 637 & 1005 \\
\hline Use condom any time you have sex? & Chi-Square $=35.49, \mathrm{p}$-value $<0.001$ & \\
\hline No & 217 & 209 \\
\hline Yes & 463 & 868 \\
\hline Residential status & Chi-Square $=85.29, \mathrm{p}$-value $<0.001$ & \\
\hline Urban & 222 & 552 \\
\hline Rural & 529 & 525 \\
\hline Sex with one partner prevents HIV? & Chi-Square $=17.77, \mathrm{p}$-value $<0.001$ & \\
\hline No & 122 & 117 \\
\hline Yes & 558 & 960 \\
\hline Wealth index status & Chi-Square $=130.41, \mathrm{p}$-value $<0.001$ & \\
\hline Poor & 622 & 619 \\
\hline Rich & 129 & 458 \\
\hline Highest education attained & Chi-Square $=173.45, \mathrm{p}$-value $<0.001$ & \\
\hline No education & 398 & 280 \\
\hline Primary & 152 & 217 \\
\hline Secondary & 195 & 512 \\
\hline Higher & 6 & 68 \\
\hline Age group & Chi-Square $=118.66, \mathrm{p}$-value $<0.001$ & \\
\hline $15-19$ & 18 & 23 \\
\hline $20-24$ & 81 & 160 \\
\hline $25-29$ & 126 & 258 \\
\hline $30-34$ & 111 & 244 \\
\hline $35-39$ & 147 & 225 \\
\hline $40-44$ & 146 & 119 \\
\hline $45-49$ & 122 & 48 \\
\hline Are you willing to take care of HIV person? & Chi-Square $=10.114, \mathrm{p}$-value $<0.001$ & \\
\hline No & 222 & 276 \\
\hline Yes & 458 & 801 \\
\hline Respondent region of residence & Chi-Square $=114.95$, p-value $<0.001$ & \\
\hline Western & 81 & 109 \\
\hline
\end{tabular}




\section{Continued}

\begin{tabular}{|c|c|c|}
\hline Central & 55 & 108 \\
\hline Greater Accra & 37 & 140 \\
\hline Volta & 61 & 81 \\
\hline Eastern & 63 & 98 \\
\hline Ashanti & 49 & 104 \\
\hline Brong-Ahafo & 80 & 113 \\
\hline Northern & 194 & 102 \\
\hline Upper East & 78 & 126 \\
\hline Upper West & 53 & 96 \\
\hline What is your religion? & Chi-Square $=47.06, \mathrm{p}$-value $<0.001$ & \\
\hline Christianity & 489 & 785 \\
\hline Islam & 169 & 250 \\
\hline Others & 93 & 42 \\
\hline $\begin{array}{c}\text { Aware HIV can be transmitted } \\
\text { during child-delivery? }\end{array}$ & Chi-Square $=4.20, \mathrm{p}$-value $<0.040$ & \\
\hline No & 212 & 287 \\
\hline Yes & 468 & 790 \\
\hline \multirow[t]{2}{*}{ Number of wives of the respondent } & $\mathrm{t}$-value $=7.62, \mathrm{p}$-value $<0.001$ & \\
\hline & 751 & 1077 \\
\hline Aware that HIV person can be healthy-looking? & Chi-Square $=41.36, \mathrm{p}$-value $<0.001$ & \\
\hline No & 191 & 166 \\
\hline Yes & 489 & 911 \\
\hline
\end{tabular}

Table 3. Unadjusted and adjusted odds ratios and 95\% confidence interval (95\%CI): Logistic regression model.

\begin{tabular}{|c|c|c|c|c|}
\hline \multirow{2}{*}{ Covariates } & \multicolumn{2}{|c|}{ Unadjusted odds ratio } & \multicolumn{2}{|c|}{ Adjusted odds ratio } \\
\hline & Odds Ratio & $95 \% \mathrm{CI}$ & Odds Ratio & $95 \% \mathrm{CI}$ \\
\hline \multicolumn{5}{|c|}{$\begin{array}{c}\text { Aware of TB-HIV } \\
\text { co-infection? }\end{array}$} \\
\hline No & 1 (reference) & & 1 (reference) & \\
\hline Yes & 0.91 & $(0.604,1.227)$ & 0.53 & $(0.165,0.893)$ \\
\hline \multicolumn{5}{|c|}{$\begin{array}{l}\text { Use condom any } \\
\text { time you have sex? }\end{array}$} \\
\hline No & 1 (reference) & & 1 (reference) & \\
\hline Yes & 0.67 & $(0.445,0.887)$ & 0.31 & $(0.054,0.573)$ \\
\hline \multicolumn{5}{|c|}{ Residential status } \\
\hline Urban & 1 (reference) & & 1 (reference) & \\
\hline Rural & -0.92 & $(-1.116,-0.721)$ & -0.26 & $(-0.540,0.024)$ \\
\hline
\end{tabular}




\section{Continued}

Sex with on partner

prevents HIV?

$\begin{array}{ccccc}\text { No } & 1 \text { (reference) } & & 1 \text { (reference) } & \\ \text { Yes } & 0.58 & (0.310,0.859) & 0.25 & (-0.076,0.568)\end{array}$

Wealth index status

Poor

1 (reference)

1.27

$(1.047,1.497)$

1 (reference)

0.46

$(0.137,0.791)$

Highest education attained
No education

Primary

Secondary

Higher

\section{Age group}

$$
\begin{aligned}
& 45-49 \\
& 15-19 \\
& 20-24 \\
& 25-29 \\
& 30-34 \\
& 35-39 \\
& 40-44
\end{aligned}
$$

Are you willing to take care of HIV person?

No

Yes

Respondent's religion

Others

Christian

Moslem

Aware HIV can be transmitted during child-delivery?

No

Number of sex partners

Aware that HIV person can be healthy-looking?

No 1 (reference)

1 (reference)

0.71

0.66

0.93

1 (reference)

1.18

0.81

0.54

0.43

0.27

0.12

1 (reference)

0.34

1 (reference)

1.27

0.59

1 (reference)

0.22

$-0.78$

$(0.010,0.432)$

$(-0.998,-0.570)$

(0.887, 1.650)

$(0.387,0.800)$
1 (reference)

$\begin{array}{ll}0.38 & (0.083,0.681) \\ 0.36 & (0.208,0.502) \\ 0.53 & (0.23,0.837)\end{array}$

1 (reference)

$\begin{array}{ll}1.29 & (0.530,2.054) \\ 0.91 & (0.667,1.148) \\ 0.57 & (0.419,0.713) \\ 0.42 & (0.313,0.534) \\ 0.25 & (0.167,0.338) \\ 0.10 & (0.030,0.179)\end{array}$

1 (reference)

$0.25 \quad(0.016,0.492)$

1 (reference)

$\begin{array}{ll}0.29 & (-0.164,0.735) \\ 0.22 & (-0.022,0.457)\end{array}$

1 (reference)

$0.24 \quad(-0.000,0.476)$

$-0.26 \quad(-0.504,-0.007)$

1 (reference)

$0.76 \quad(0.527,0.998)$
0.41
$(0.137,0.679)$ 
The results also revealed that those who are rich are more likely to test for HIV relative to those who are not rich and those with primary, secondary and higher education are more likely to ever test for HIV relative to those without education. Also, the results revealed that, in terms of the magnitude of the effects, higher education are more likely to ever test for HIV $(\mathrm{OR}=0.53)$ with secondary $(\mathrm{OR}=0.36)$ and primary $(\mathrm{OR}=0.38)$ education has almost comparable effects on HIV testing. The results revealed that the younger you are, the higher the likelihood to test for HIV. It can be observed that the youngest age group (15 - 19) are more likely (1.18) to test for HIV, followed by 20 - 24, 24 29, 30 - 34, 35 - 39, and 40 - 44. These results are probably due to the fact that younger people are more likely to engage new sexual contracts/relationship such as "boy-girlfriend", marriages, and new sexual partners. Being a Christian or a Moslem increases the likelihood that you test for HIV relative to respondents from traditional and other religions. In terms of the magnitude of religious effect on HIV testing (ever test for HIV), Christians are more likely (0.29) than Moslems (0.22), to ever test for HIV. However, after adjusting for the effects of other risk factors, we realized that religious effect of being a Christian, on ever test for $\mathrm{HIV}$, is not statistically significant. Our analyses also revealed if you are willing to take care of HIV person, you are more likely to ever test for HIV. However, this effect is not statistically significant after controlling for additional risk factors of HIV testing. Those who have knowledge that HIV can be transmitted during child-delivery are more likely to ever test for HIV relative to those who have no knowledge. The likelihood that one would ever test for HIV increases with an increasing number of sexual partners. Having the knowledge that HIV infected person may look healthy increases the likelihood of such individual to ever test for HIV.

Our initial analyses of the HIV testing (on regional basis) suggest that whether an individual ever tested for HIV is significantly (see Table 2) associated with the region (Chi-Square $=114.95$, p-value $<0.001$ ). Hence, we considered comparative analyses of the HIV data on regional basis. The purpose of the comparative analyses is to investigate the magnitude (direction) and significance of the effects of the various risk factors variables (considered in this study) on the status of whether an individual has ever tested for HIV. This will help us to study regional variation among the risk factors. Although, we will not present the results of the risk factors and their effects on ever test for HIV (on regional basis-10 regions) we will discuss them.

For the Western region, those who are rich are more likely $(\mathrm{OR}=1.13,95 \%=$ $0.119,2.141)$ to ever test for HIV relative to those who are poor and those aged 25 - 29 are more likely $(\mathrm{OR}=0.72,95 \%=0.211,1.235)$ to ever test for HIV when compared with the other age groups. The rest of the risk factor variables have no significant effect on the status of ever test for HIV.

Those in Central region and aged $20-24(\mathrm{OR}=1.15,95 \%=0.299,2.000), 25-$ $29(\mathrm{OR}=0.68,95 \%=0.188,1.172), 30-34(\mathrm{OR}=0.65,95 \%=0.258,1.036)$, or $35-39(\mathrm{OR}=0.37,95 \%=0.071,0.679)$ are more likely to ever test for HIV. This 
means that there is an increase chance/risk to ever test for HIV if an individual in the Central region fall within these age categories.

In Greater Accra, all the risk factors (presented in Table 3) have no significant effect on the status of whether an individual has ever tested for HIV except individuals aged 20 - 24. This means that those aged 20 - 24 in the Greater Accra region are more likely to ever test for HIV.

In the Volta region, having the knowledge of HIV-TB co-infection has significant effect on the status of ever tested for HIV indicating an increase in the likelihood $(\mathrm{OR}=1.87,95 \%=0.298,3.45)$ to ever test for HIV. There is approximately $(\mathrm{OR}=2$-folds, $95 \%=0.434,3.406)$ increase in the risk of testing for HIV if you are a Christian and reside in the Volta region. In terms of magnitude of risk factors effects, those aged $20-24$ more likely $(\mathrm{OR}=1.70,95 \%=0.589$, $2.809)$ to ever test for HIV in the Volta region followed by $25-29$ (OR = 1.03, $95 \%=0.375,1.686), 30-34(\mathrm{OR}=0.88,0.410,1.355)$, and $35-39(\mathrm{OR}=0.66$, $95 \%=0.264,1.052)$ age groups.

In the Eastern region, secondary and higher education, age groups 20 - 24, 25 - 29, and 30 - 34 have a significant effect on whether an individual has ever tested for HIV. This implies that those who have attained secondary $(\mathrm{OR}=0.53$, $95 \%=0.139,0.911)$ and higher education $(\mathrm{OR}=0.64,95 \%=0.104,1.169)$ are more likely to ever test for HIV. For Ashanti region, higher education, age groups 15 - 19, 20 - 24, and 25 - 29 significantly predict the status of whether an individual ever tested for HIV.

Furthermore, our analyses by regions show that condom use anytime one has sex, higher education, age groups 20 - 24, 25 - 29, 30 - 34, and 35 - 39 are significant risk factors of HIV testing in the Brong-Ahafo region. In terms of the magnitude of risk factors effects, the youngest age group $20-24$ is the highest followed by 25 - 29, 30 - 34, and 35 - 39 age groups. These risk factors show the increase in the likelihood of HIV testing.

For the Northern region, being aware that a person with HIV may look healthy increases the likelihood $(\mathrm{OR}=0.80,95 \%=0.140,1.454)$ of $\mathrm{HIV}$ testing and there is $\mathrm{OR}=2$-folds, $95 \%=0.657,3.644$ increase for those who are rich to ever test for HIV relative to those who are poor. Moslems in the Northern region are more likely $(\mathrm{OR}=1.01,95 \%=0.400,1.615)$ to ever test for HIV relative to the other religions and the younger the age group, the higher the likelihood of testing for HIV.

The analyses revealed that type of residence (urban or rural), awareness of HIV-TB co-infection, willingness to care for HIV person, age groups 20 - 24, 25 - 29, and 30 - 34 are the significant risk factors of HIV testing in the Upper East region. This means that those who reside in rural areas are less likely $(\mathrm{OR}=$ $-1.26,95 \%=-2.264,-0.253)$ to ever test for HIV relative to those who reside in the urban areas. Those who are aware of HIV-TB co-infection are more likely $(\mathrm{OR}=0.88,95 \%=0.067,1.699)$ to ever test for HIV. Willingness to care for HIV person increases the likelihood of testing for HIV and age groups 20 - 24, 25 29, and $30-34$ are more likely to ever test for HIV. Knowledge that an HIV in- 
fected person may look healthy increases the likelihood of HIV testing among people in the Upper East. Higher education (beyond secondary education) is a significant determinant of HIV testing among residents in the Upper East region.

HIV-TB co-infection awareness, religion, age group, and willingness to care for HIV person are the significant risk factors of HIV testing in the Upper West region. That is, there is OR $=2.21$-folds, $95 \%=0.792,3.626$ increase in the likelihood of ever testing for HIV among individuals who are aware HIV-TB co-infection; those who are Christians are less likely ( $\mathrm{OR}=-2.52,95 \%=-4.631$, -0.406) to ever test for HIV relative to those who belong to other religions; and there is approximately $\mathrm{OR}=4$-folds, $95 \%=2.074,5.475$ increase in the likelihood of testing for HIV among individuals who are willing to take care of HIV person. Individuals within the age groups 20 - 24, 25 - 29, 30 - 34, and $34-39$ are more likely to ever test for HIV relative to older age groups.

\section{Discussions and Conclusions}

In this paper, we investigated the effects of various (both motivating and discouraging) risk factors on individuals' decision to ever test for HIV. Knowing one's HIV/AIDS status is the first step for ensuring timely enrollment of HIV/AIDS individuals on anti-retroviral therapy (ART). This will obviously reduce the spread of HIV and HIV-related mortalities. Thus, one of the objectives to end the AIDS epidemic by 2030 may not be achievable if the majority of HIV/AIDS persons have their HIV/AIDS statuses unknown. The target (by 2020 ) is to reduce new HIV infections to fewer than 500,000 globally and a reduction in deaths from AIDS-related illness to fewer than 500,000 globally (which represents a $75 \%$ reduction in new infections and mortalities due to HIV-related illness).

This study focuses on factors that influence the Ghanaian's decision to ever test for HIV. So in order to identify factors that influence one's decision to ever test for HIV, we used the 2014 Ghana Demographic and Health Survey (GDHS) data. The GDHS data contain "ever tested for HIV" outcome variable of interest as well as various potential determinants/risk factors of the status of the outcome variable. Two statistical approaches, the Chi-Square test statistic and the logistic regression model, are applied to these data.

First, we applied the Chi-Square test statistic to investigate the degree (significance) of the association between the outcome variable and each of the various risk factors/potential determinants of the status of the outcome variable. The Chi-Square test statistic results revealed that religion, education, number of wives, geographical location (urban or rural), region, age group, condom use anytime you have sex, sex with one partner can prevent HIV, wealth index, aware of HIV-TB co-infection, willing to care for HIV person, aware that HIV can be transmitted during child-delivery, and aware that HIV infected person can be healthy-looking are significantly associated with the outcome variable and hence are potential determinants of one's decision to ever test for HIV. 
These variables were then used in our further analyses under the logistic regression model/analysis.

Second, we applied the logistic regression model to the data in order to establish the relationship between the outcome variable (ever tested for HIV) and various risk factors found to be significant under the Chi-Square test statistic. This model is also used to investigate the magnitude and degree (significance) of the effects of the various potential determinants of the status of the outcome variable. After controlling for the risk factors, the logistic regression model's results showed that there is significant increase in the chance to ever test for HIV if an individual: 1) is aware of HIV-TB co-infection, 2) uses condom any he/she has sex, 3) is rich, 4) has some level of education, 5) is less than 45 - 49 years old (the younger the age group the higher the chance),6) is willing to take care of HIV person, and 7) is aware that HIV infected person can be healthy-looking. There is a significant reduction in the chance to ever test for HIV with increasing number wives. This seems to suggest that those who have many wives do not care much to know their HIV/AIDS status as against those who believe that having sex with one partner can prevent HIV. However, this increase in the chance to ever test for HIV, if you believe that having sex with partner can prevent HIV, is not statistically significant. There is an insignificant reduction in the chance to ever test for HIV if an individual resides in a rural community. Being aware of HIV can be transmitted during child-delivery increases the likelihood to ever test for HIV. However, this increase is not statistically significant.

Generally, the analyses of data set by regions revealed that age is the common risk factors/potential determinants of one's decision to ever test for HIV. For instance, in the Western, Central, Greater Accra, Volta, Eastern, Brong-Ahafo, Upper East, and Upper West regions, age is a significant determinant of ever tested for HIV. Education is a significant determinant of ever tested for HIV in the Eastern, Brong-Ahafo and Upper East regions. Knowledge on HIV-TB co-infection is a significant determinant of ever tested for HIV in the Upper West, Upper East, and Volta regions. Religious belief is a significant determinant of ever tested for HIV in the Upper West, Northern, and Volta regions.

Wealth index is a significant risk factor of ever tested for HIV in the Western and Northern regions and condom use anytime an individual has sex is the only significant determinant of ever tested for HIV in the Brong-Ahafo region. Being aware that an HIV infected person may look healthy as well significantly increases the likelihood to ever test for HIV among residents in the Northern and Upper East region and willingness to care for HIV infected person is significant in the Upper East and West regions. It is only in the Upper East region that geographical location (urban or rural) has a significant effect on ever tested for HIV. The only risk factors that are not significant determinants of ever tested for HIV (in any of the 10 regions) are the number of partners of the respondent and awareness that HIV can be transmitted during child-delivery.

It can be observed that age is the common significant risk factors ever tested 
for HIV across the 10 regions in Ghana. We, therefore, recommend that resources should be allocated for more education on these significant risk factors in order to increase the likelihood of testing for HIV/AIDS in Ghana.

\section{Notes on Contributor(s)}

AI carried out the literature review, statistical analyses, interpretation of results, and wrote the manuscript. KOA, FKB, BM, and JJAA contributed to the interpretation and reviewing or proof-reading of the manuscript. All authors have read and approved the final version of the manuscript.

\section{Ethics Approval (and Consent to Participate)}

Ethical approval and consent to participate statements can be found on http://dhsprogram.com/What-We-Do/Protecting-the-Privacy-of-DHS-Survey-R espondents.cfm, approved by the ICF International Institutional Review Board (IRB).

\section{Availability of Data and Materials}

We do not have permission to distribute the data.

\section{Conflicts of Interest}

The authors declare no conflicts of interest regarding the publication of this paper.

\section{References}

[1] Joint United Nations Programme on HIV/AIDS, et al. (2018) Miles to Go: Closing Gaps, Breaking Barriers, Righting Injustices. Geneva.

[2] Joint United Nations Programme on HIV/AIDS, et al. (2013) Global Report: Un-Aids Report on the Global Aids Epidemic 2013. Geneva.

[3] Joint United Nations Programme on HIV/AIDS, et al. (2018) Un-Aids Data 2017. Geneva.

[4] Mkandawire, P. (2017) Assessing Factors Associated with HIV Testing among Adolescents in Malawi. Global Public Health, 12, 927-940. https://doi.org/10.1080/17441692.2016.1213125

[5] World Health Organization, et al. (2007) Towards Universal Access: Scaling up Priority HIV/Aids Interventions in the Health Sector.

[6] Woodford, M.R., Chakrapani, V., Newman, P.A. and Shunmugam, M. (2016) Barriers and Facilitators to Voluntary HIV Testing Uptake among Communities at High Risk of HIV Exposure in Chennai, India. Global Public Health, 11, 363-379. https://doi.org/10.1080/17441692.2015.1057757

[7] Rouhani, S.A., O’Laughlin, K.N., Faustin, Z.M., Tsai, A.C., Kasozi, J. and Ware, N.C. (2017) The Role of Social Support on HIV Testing and Treatment Adherence: A Qualitative Study of HIV-Infected Refugees in Southwestern Uganda. Global Public Health, 12, 1051-1064. https://doi.org/10.1080/17441692.2015.1132472

[8] King, E.J., Maman, S., Dudina, V.I., Moracco, K.E. and Bowling, J.M. (2017) Motivators and Barriers to HIV Testing among Street-Based Female Sex Workers in St. 
Petersburg, Russia. Global Public Health, 12, 876-891. https://doi.org/10.1080/17441692.2015.1124905

[9] Tenkorang, E.Y. and Owusu, G.A. (2010) Correlates of HIV Testing among Women in Ghana: Some Evidence from the Demographic and Health Surveys. AIDS Care, 22, 296-307. https://doi.org/10.1080/09540120903193716

[10] MacPhail, C.L., Pettifor, A., Coates, T. and Rees, H. (2008) "You Must Do the Test to Know Your Status": Attitudes to HIV Voluntary Counseling and Testing for Adolescents among South African Youth and Parents. Health Education \& Behavior, 35, 87-104. https://doi.org/10.1177/1090198106286442

[11] Obermeyer, C.M., Sankara, A., Bastien, V. and Parsons, M. (2009) Gender and HIV Testing in Burkina Faso: An Exploratory Study. Social Science \& Medicine, 69, 877-884. https://doi.org/10.1016/j.socscimed.2009.07.003

[12] Sambisa, W., Curtis, S. and Mishra, V. (2010) Aids Stigma as an Obstacle to Uptake of HIV Testing: Evidence from a Zimbabwean National Population-Based Survey. AIDS Care, 22, 170-186. https://doi.org/10.1080/09540120903038374

[13] Boswell, D. and Baggaley, R. (2002) Voluntary Counseling and Testing and Young People: A Summary Overview.

[14] Uganda Project Partners Horizons Program, Kenya Project Partners (2001) HIV Voluntary Counseling and Testing among Youth: Results from an Exploratory Study in Nairobi, Kenya, and Kampala and Masaka, Uganda.

[15] Yoder, P.S. and Matinga, P. (2004) Voluntary Counselling and Testing (VCT) for HIV in Malawi: Public Perspectives and Recent VCT Experiences.

[16] Luginaah, I.N., Yiridoe, E.K. and Taabazuing, M.-M. (2005) From Mandatory to Voluntary Testing: Balancing Human Rights, Religious and Cultural Values, and HIV/Aids Prevention in Ghana. Social Science \& Medicine, 61, 1689-1700. https://doi.org/10.1016/j.socscimed.2005.03.034

[17] Nuwaha, F., Kabatesi, D., Muganwa, M. and Whalen, C.C. (2002) Factors Influencing Acceptability of Voluntary Counseling and Testing for HIV in Bushenyi District of Uganda. East African Medical Journal, 79, 626-632. https://doi.org/10.4314/eamj.v79i12.8669

[18] Castle, S. (2003) Doubting the Existence of Aids: A Barrier to Voluntary HIV Testing and Counselling in Urban Mali. Health Policy and Planning, 18, 146-155. https://doi.org/10.1093/heapol/czg019

[19] Iddrisu, A.-K. and Gumedze, F. (2018) Application of Sensitivity Analysis to Incomplete Longitudinal CD4 Count Data. Journal of Applied Statistics, 46, 754-769. https://doi.org/10.1080/02664763.2018.1510476

[20] Iddrisu, A.-K. and Gumedze, F. (2019) An Application of a Pattern-Mixture Model with Multiple Imputation for the Analysis of Longitudinal Trials with Protocol Deviations. BMC Medical Research Methodology, 19, 10. https://doi.org/10.1186/s12874-018-0639-y

[21] McHugh, M.L. (2013) The Chi-Square Test of Independence. Biochemia Medica, 23, 143-149. https://doi.org/10.11613/BM.2013.018

[22] Hosmer Jr., D.W., Lemeshow, S. and Sturdivant, R.X. (2013) Applied Logistic Regression, Volume 398. John Wiley \& Sons, Hoboken. https://doi.org/10.1002/9781118548387

[23] Menard, S. (2002) Applied Logistic Regression Analysis, Volume 106. Sage, Thousand Oaks. https://doi.org/10.4135/9781412983433

[24] Allison, P.D. (2012) Logistic Regression Using SAS: Theory and Application. SAS 
Institute.

[25] Abdul-Karim, I., Dominic, O. and Bashiru, M. (2019) Investigating the Determinants of Maternal Care Services Utilization in the Brong Ahafo Region of Ghana. Open Journal of Statistics, 9, 927-940.

[26] R Core Team, et al. (2016) R: A Language and Environment for Statistical Computing.

[27] R Core Team (2014) R: A Language and Environment for Statistical Computing. R Foundation for Statistical Computing, Vienna.

[28] Healy, K. (2005) Book Review: An R and s-plus Companion to Applied Regression. Sociological Methods \& Research, 34, 137-140. https://doi.org/10.1177/0049124105277200

[29] LP StataCorp, et al. (2007) STATA: Data Analysis and Statistical Software. Special Edition Release, 10, 733.

[30] Statt Stata (2013) Release 13. Statistical Software. StataCorp LP, College Station. 